\title{
Participatory ecological monitoring of the Alaotra wetlands in Madagascar
}

\author{
HERIZO T. ANDRIANANDRASANA*, JONAH \\ RANDRIAMAHEFASOA, JOANNA DURBIN, \\ RICHARD E. LEWIS and JONAH H. RATSIMBAZAFY \\ Durrell Wildlife Conservation Trust Madagascar Programme, BP 8511, Antananarivo 101, Mada- \\ gascar; *Author for correspondence (e-mail: dw.madagascar@durrell.org; phone: + 261-20-22- \\ 212-54; fax: + 261-20-22-357-48)
}

Received 31 March 2004; accepted in revised form 10 November 2004

Key words: Biodiversity, Ecological monitoring, Fish, Lac Alaotra, Lemurs, Locally-based monitoring, Madagascar, Participation, Waterbirds, Wetlands

\begin{abstract}
Participatory ecological monitoring is a realistic and effective approach in wetlands such as Alaotra, Madagascar, where important biodiversity is found in an area with high human population density. Since 2001, Durrell Wildlife Conservation Trust, government technical services, regional non-governmental organisations and local communities have collected data on key species, such as waterbirds, a locally endemic lemur and useful natural resources. The monitoring was linked with environmental quizzes and an inter-village competition, which helped raise interest in the monitoring and publicise results. The monitoring has assisted wetland management by guiding amendments to and increasing respect for the regional fishing convention, raising awareness, catalysing marsh management transfer to communities and stimulating collaboration and good governance. The sustainability of the monitoring scheme and the usefulness of the data for detecting trends and guiding local managements are discussed.
\end{abstract}

\section{Introduction}

Madagascar, one of the world's 12 biodiversity hotspots (Mittermeier et al. 1994), is most famous for its lemurs, all of which are endemic to Madagascar. Over $99 \%$ of amphibians are endemic (Glaw and Vences 2003), 96\% of reptiles (Raxworthy 2003), 85\% of vascular plants (Gautier and Goodman 2003) and $51 \%$ of birds (Hawkins and Goodman 2003). Nearly all Madagascar's endemic species reside in forests and wetlands.

The Alaotra wetlands constitute the largest wetlands in the country. Alaotra is an example of a shallow wetland that is a highly productive ecosystem, very valuable for people and biodiversity, but also vulnerable to degradation, particularly in terms of sedimentation. This process is easily affected by human activities, such as agriculture causing increased erosion and siltation, and introduction of aquatic plants and fish causing dramatic changes in the trophic structure of the ecosystem.

Since 2001, Durrell Wildlife Conservation Trust (Durrell Wildlife) has organised annual participatory ecological monitoring in Alaotra, both to evaluate the 
effectiveness of management initiatives and to reinforce local commitment to management by demonstrating the impacts. Participatory methods were used to facilitate data collection and also to develop broader local knowledge of the wetland biodiversity and resources and the level of threats. Involving local residents in monitoring may foster greater local ownership of resource monitoring and management and help ensure future sustainability (Danielsen et al. 2003). The goal of this scheme is to detect natural and/or human-induced changes in the state of the biodiversity and natural resources as an aid to evaluating and improving management.

While locally-based monitoring of freshwater wetlands are undertaken in several Northern countries (e.g. Engel and Voshell 2002; Boylen et al. 2004) there are few documented examples of participatory wetland monitoring from developing countries (see Townsend et al. 2005 (this issue) for an example from Ecuador). The paucity of wetland monitoring schemes in developing countries is surprising because wetlands often provide substantial direct and indirect benefits to their residents. Local stakeholders may therefore be particularly interested in participating in monitoring initiatives. This paper examines the wetland monitoring programme at Alaotra, presenting initial results and assessing current and potential impact. The sustainability of the monitoring scheme and the usefulness of the data for detecting trends and guiding local management are also evaluated.

\section{Study area}

The Alaotra wetlands is located in central eastern Madagascar $\left(17^{\circ} 02^{\prime}\right.$ $18^{\circ} 10^{\prime} \mathrm{S}, 48^{\circ} 00^{\prime}-48^{\circ} 40^{\prime} \mathrm{E}$ ). Lake Alaotra is 20,000 ha, has an average depth of $2-4 \mathrm{~m}$ and is situated at $750 \mathrm{~m}$ asl. Surrounding the lake are 23,000 ha of marshes dominated by papyrus Cyperus madagascariensis and reeds Phragmites communis and then 120,000 ha of rice-fields within a watershed encompassing 722,500 ha and reaching $1300 \mathrm{~m}$ at its highest point (Andrianandrasana et al. 2002).

Three taxa are endemic to Alaotra, all of which are critically endangered: Alaotran gentle lemur Hapalemur griseus alaotrensis which has shown a 30\% decline over 5 years (Mutschler et al. 2001), Alaotra little grebe Tachybaptus rufolavatus and Madagascar pochard Aythya innotata. These two endemic bird species may already be extinct, probably because of exotic fish introduction and excessive drowning in fishing nets. Local people claim that the carnivorous introduced fish Channa striata has been a significant predator of young of diving species such as the endemic grebe, which had limited flight capacity (Hawkins et al. 2000). Of the 50 waterbird species recorded at the lake (Langrand 1995), eight are Madagascar endemics. Six fish species are Madagascar endemics. 
The endemic fauna at Alaotra is threatened due to major environmental changes including:

- habitat degradation,

- over-hunting,

- over-fishing,

- competition and predation by introduced fish species,

- siltation from erosion,

- pollution by human waste, fertilisers and pesticides and

- invasion of introduced aquatic plants (Pidgeon 1996).

The human population living in the Alaotra watershed has increased five-fold from 109,000 in 1960 (Pidgeon 1996) to approximately 550,000 people today (PRD 2003), the majority of whom depend on rice cultivation and fishing for their livelihood. The Alaotra region is the most important rice production area in the country and one of the most important for inland fisheries.

Since a peak in the 1960s of 4,000 tonnes (Pidgeon 1996), annual fish catches have declined to around 2,000 tonnes (Razanadrakoto 2004) probably as a result of over-fishing, acidification and other changes related to introduced species and siltation. The number of fishermen increased from 1,000 in 1963 (Pidgeon 1996) to 4,000 in 2003 (Razanadrakoto 2004) and fishing intensified following the introduction of Tilapia and seine nets in 1960s. There are now 50 nets more than $1 \mathrm{~km}$ long and some nets have mesh sizes down to $1 \mathrm{~mm}$ (Razanadrakoto 2004).

Once forested, most hills around the lake are now denuded, causing development of accentuated erosion gullies which deposit infertile laterite and sands on lower land resulting in loss of rice fields, silting of irrigation canals and acidification of the lake. Only 81,500 ha are now under cultivation giving an annual rice production of around 250,000 tonnes (Rakotonierana 2004). Since the 1950s, the water lilies (Nymphea spp.) that covered large parts of the lake (Pidgeon 1996) have almost disappeared and over $70 \%$ of the waterways and lakes within the marshes have been invaded by Azolla sp., Salvinia molesta and Eichhornia crassipes (Andrianandrasana 2002). Most of the marshes, home to the lemurs, have been transformed into rice fields, while remaining marshes have been burned frequently either in an attempt to create further rice fields, to create pasture for cattle, or to create open areas for fishing as a result of choking of traditional fishing areas by invasive plants.

Durrell Wildlife began research in 1986 on local endemics at Alaotra and began a public awareness campaign from 1997 involving village festivals and environmental education in schools. This catalysed grass-roots interest in marsh conservation, as villagers recognised that they provide a refuge and breeding ground for fish and birds, provide materials for houses- as well as woven baskets and mats and dried rhizomes for cooking fuel. They furthermore form a barrier protecting the lake from siltation and pollution. Building on this local interest in marsh conservation, a series of meetings and workshops at village-, commune- (group of villages) and regional levels stimulated local conservation and management initiatives from 2001. 
Nine communities received resource-management rights through a 3-year renewable contract with the State (the legal owner of the lake and marshes) giving them management control over $35 \%$ of all the marshes. These management transfer contracts give communities the right to exclude people from outside their community from using resources, to receive fees for resource use, to charge fines to those who don't respect the rules they establish and protect the area from private land claims. The entire marsh area will soon be legally managed by surrounding communities. Sustainable use and marsh protection have been developed through the creation of by-laws ('dina') and federations of community associations. Regional fishing laws have been adopted since 1998 that control fishing practices with the aim of maintaining fish stocks and have become progressively more effective with enforcement of a 2-month closed fishing period from 2001.

The entire Alaotra watershed was designated as a Ramsar site according to the Convention on Wetlands in 2003, formalising the new regional and national commitment to conserving its biodiversity and maintaining the ecosystem functions through sustainable use. A regional organisation representing all stakeholders has been created to coordinate wetland management. The entire lake and marshes will become a new type of protected area (IUCN Category VI) currently under development in Madagascar (Site de Conservation) including a strict conservation area (no extractive use) of 8,900 ha.

\section{Methods}

\section{Logistical organisation of monitoring}

Monitoring began in 2001 with five key sites (villages known to have lemurs in their marshes) covering $80 \%$ of existing marshes, and was extended to a total of 16 sites in 2002, covering more than $98 \%$ of the marshes (Figure 1).

In 2002 and 2003 the monitoring took 3 months, from February to April, when lemurs are most active and the water level enables use of canoes in the marshes and after dry season fires and the closed fishing season (OctoberDecember). Each site takes 3-4 days; half a day meeting with villagers to explain and organise the work, 2 days of data collection and a final half-day for a public environmental quiz and to present results of the monitoring. A summary of the results is presented orally to the assembled public after the quiz by one of the village members of the monitoring team and copies, together with all the data sheets, are signed and kept by the monitoring team, by the president of the community association and by local authority (mayor).

Monitoring teams at each site consist of up to 17 people: 10 villagers and seven technicians. Following a preparatory visit a week before, the participants are chosen at the initial meeting on the first day of the monitoring to which all community members are invited. Selection criteria include a good knowledge 


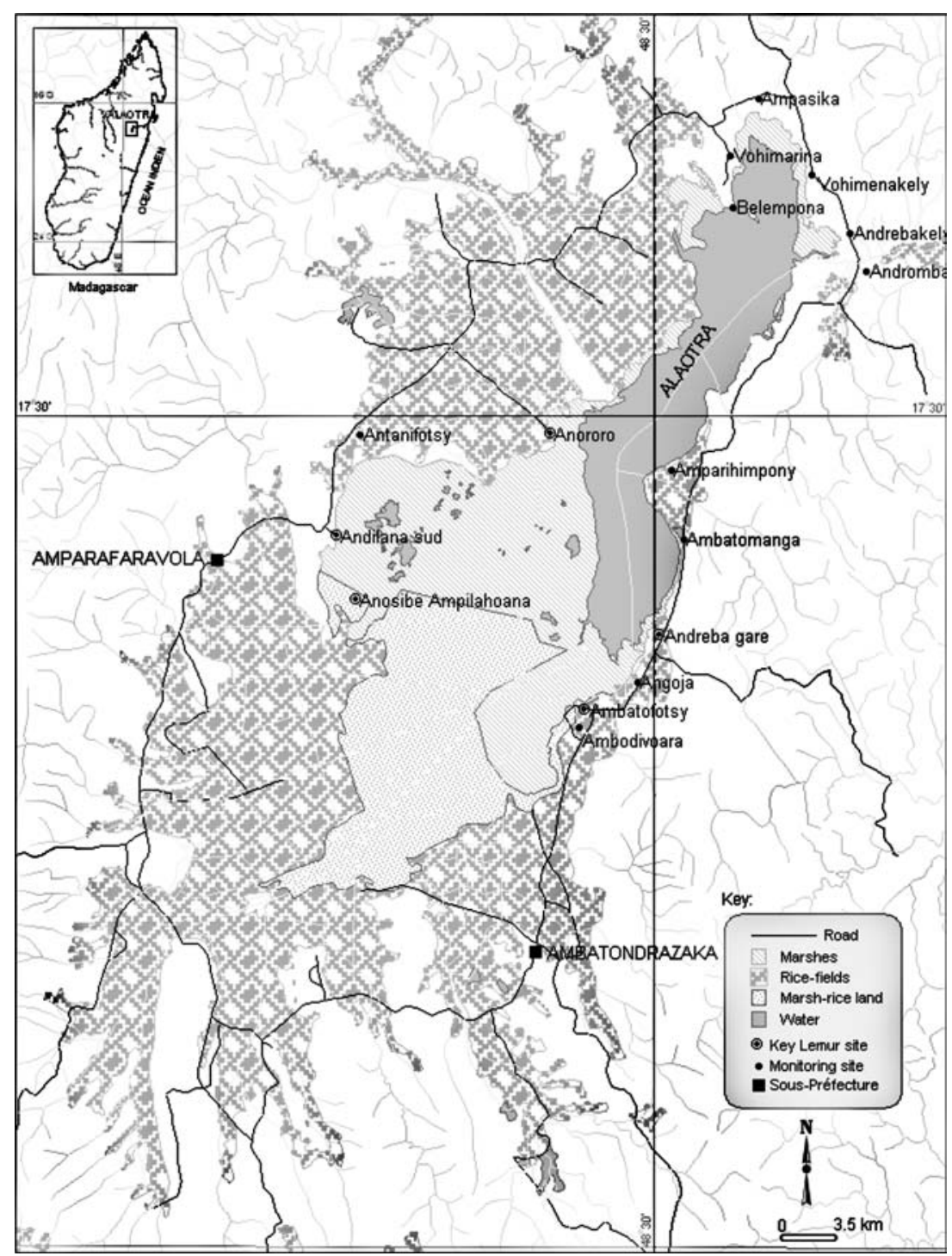

Figure 1. Map of the Alaotra wetlands, Madagascar.

of marshes and animals and literacy. Candidates are discussed after which the village head (administrative appointment) and traditional clan leaders (Tangalamena) propose the participants, trying to ensure that they are knowledgeable and will work openly and assiduously with the monitoring team. Individuals can also volunteer for the work and must be accepted by the village meeting. They are paid 12,500 Malagasy francs (fmg) per day (\$2), which is less than average earnings from fishing. Most participants want to 
continue the monitoring in subsequent years. Technicians are from the regional Water and Forests service, the Fisheries service, Durrell Wildlife, regional development NGOs plus two local experts (lemur and bird specialists who have worked with research teams). Durrell Wildlife technicians have university degrees whereas other technicians have secondary school education. Since 2002, the village participants, most of whom have primary school education, have received training in data collection.

\section{Environmental quiz}

Since 2003, a quiz has been used to evaluate local knowledge and as an occasion to raise environmental awareness. Approximately 50 questions are posed to adults and children in separate groups. The questions are divided into three sets based on biodiversity, ecology and environmental rules and regulations.

The quiz takes about $4 \mathrm{~h}$ including speeches from elders followed by a small party with traditional singing and dancing on an environmental theme. Prizes such as t-shirts, soap, pens and exercise books are given to winners. Typically a community will receive prizes of a total value of $250,000 \mathrm{fmg}(\$ 40)$.

\section{Participatory ecological monitoring as a competition}

A competition was launched to increase local interest in the monitoring, to publicise results of the monitoring and to strengthen short-term positive incentives for good environmental management until longer-term benefits became clearer. In 2002, the 16 sites were divided into three groups according to their location and the extent of marsh found at the site. A marking scheme was used based on the monitoring criteria outlined in Table 1 with higher marks awarded for positive environmental results (e.g. smaller areas of marsh burned). Sites only competed against others from the same group.

Results were announced two months after the monitoring and 1,300,000 fmg (\$225) was awarded for first prize in each group, 900,000 fmg (\$150) for second prize and 400,000 fmg (\$70) for third and fourth places. Prizes were given as the equivalent value in materials chosen by the community such as material towards building a well or a school.

From the beginning of the monitoring through to final judging, regional radio and TV publicised the competition with a special programme for the prize-giving ceremonies attended by local and national dignitaries. An annual monitoring report is given to all the regional Government services, other partners and journalists. 


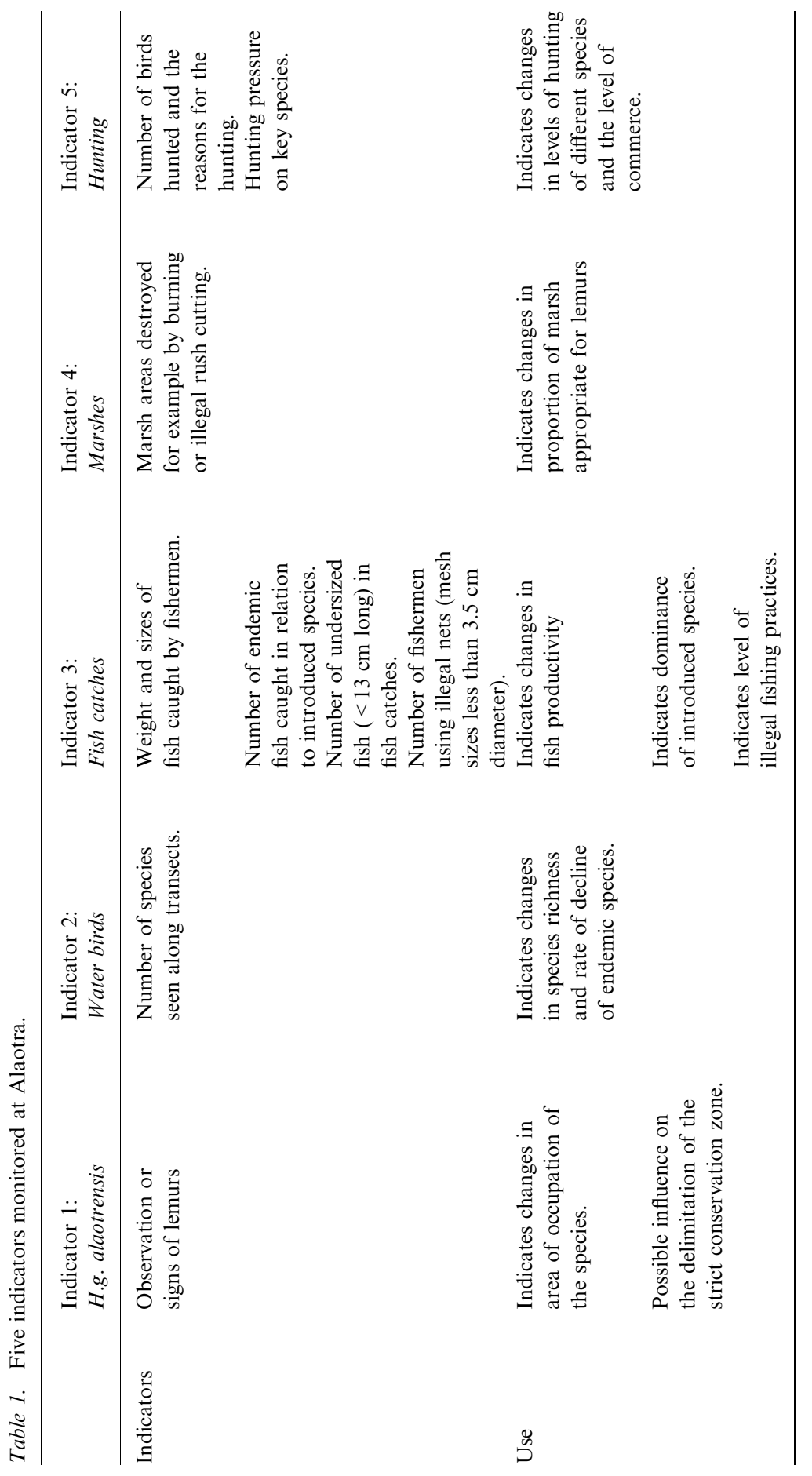




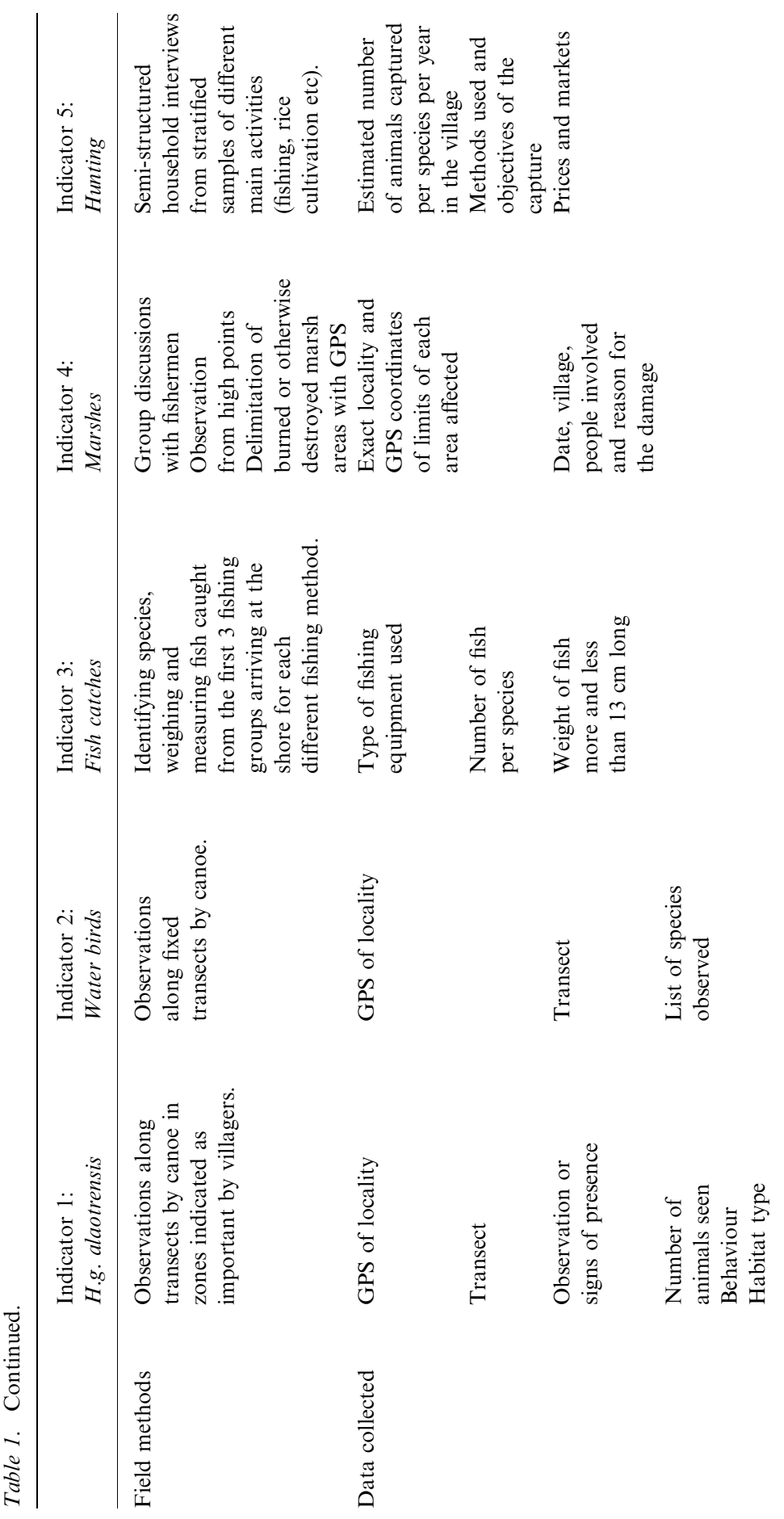




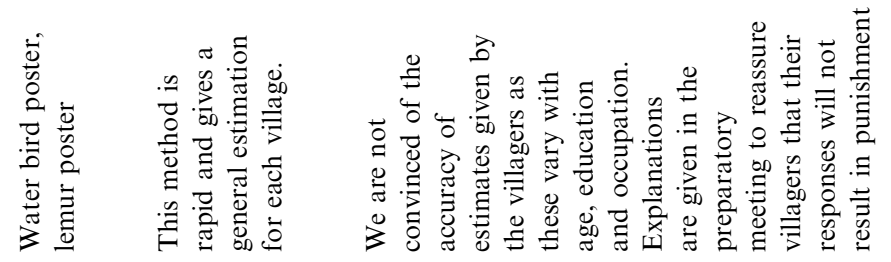

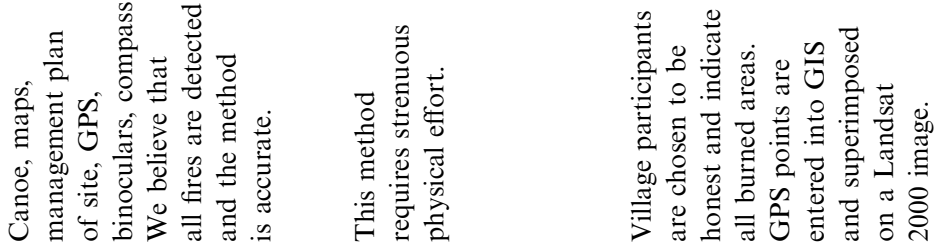

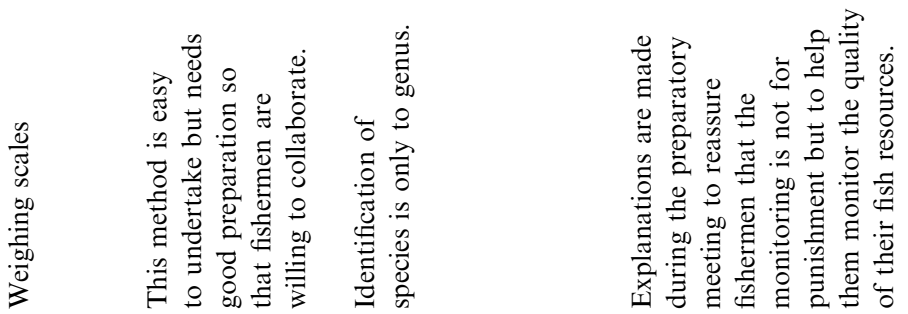

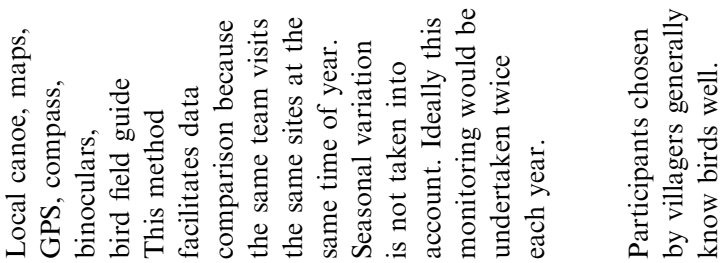

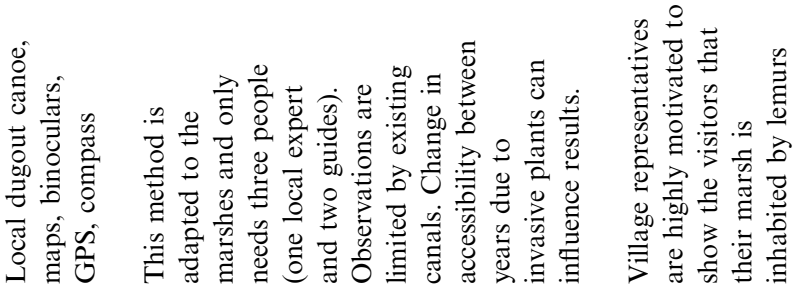

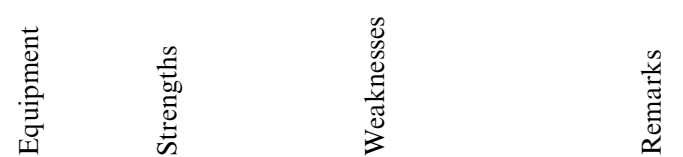


Table 2. Area of Alaotra marsh burned from 2000 to 2003.

\begin{tabular}{lcccc}
\hline Year & 2000 & 2001 & 2002 & 2003 \\
\hline Marsh area burned (ha) & 7300 & 4430 & 392 & $2500-2600^{\mathrm{a}}$ \\
$\%$ of total marsh area $(23,000 \mathrm{ha})$ & 31.7 & 19.3 & 1.7 & $>10^{\mathrm{a}}$ \\
\hline
\end{tabular}

${ }^{a}$ Estimated by Durrell Wildlife, September 2003. Precise figure to be determined during 2004 monitoring. Areas recorded in a monitoring visit were from fires in the dry season of the previous year.

\section{Results}

\section{Examples of key findings of the monitoring}

The participatory monitoring shows promise as a tool to enable the government and villagers to keep track of the annual extent of marsh burned Table 2.

The monitoring showed a considerable reduction in marsh fires from 2000 to 2002. The increase in 2003 is mainly due to one large fire. Durrell Wildlife increased its education activities from 2000 and launched the first participatory ecological monitoring from 2001, at the same time that the Government strengthened application of laws banning bush fires.

The monitoring can also assist the government and villagers to assess the impact of management on fisheries. No Madagascar endemic species were observed since 2001 and fish catches are dominated by introduced Tilapia spp. The average catch rate varies between 0.2 and $0.4 \mathrm{~kg} /$ person $/ \mathrm{h}$ (Table 3) with a significant increase from 2002 to 2003 (paired $t$-test $p \leq 0.05$ ), although the longer term data will be important to show if this is a real trend. Regional bylaws ban catching fish less than $13 \mathrm{~cm}$ long yet there is still a low appearance of these in catches.

It should be noted that the two-month closed fishing season (15 October to 15 December) has only been strictly applied since 2002, which, in addition to the gradual improvement in application of the regional fishing by-laws, could account for this promising increase in fish catches.

Table 3. Monitoring of fish catches at Alaotra, Madagascar, from 2001 to 2003.

\begin{tabular}{lccc}
\hline Year & $2001^{\mathrm{a}}$ & 2002 & 2003 \\
\hline Number of fish catches examined & 59 & 121 & 151 \\
Total mass of catches $(\mathrm{kg})$ & 314.9 & 652.6 & 1089.4 \\
Average catch/person $(\mathrm{kg})$ & 5.33 & 5.39 & 7.21 \\
Average catch rate $(\mathrm{kg} / \mathrm{person} / \mathrm{h})$ & 0.26 & 0.23 & 0.39 \\
Fish $<13 \mathrm{~cm}$ long $(\%$ of catch) & 17.6 & 18.7 & 15.8 \\
Number of endemic/indigenous species observed & 0 & 0 & 0 \\
Proportion of Tilapia by weight $(\%$ of catch) & 84.6 & 86.1 & 87.1 \\
\hline
\end{tabular}

${ }^{a} 2001$ figures are from the five key sites, whereas 2002 and 2003 are from 16 sites. 
Village surveys indicated that large numbers of birds are hunted. 5600 birds were hunted in the 16 villages in 2003, and 4,800 birds in 2002, most of which were ducks and other waterbirds that hunters caught in traps and by hand. The birds hunted are mostly species that are resident in Alaotra wetlands: Dendrocygna viduata, Sarkidiornis melanotos, Anas melleri, Anas erythrorhyncha, Anas hottentota and Fulica cristata. These figures are the total for 16 villages of the mean of responses given by different people on the estimated numbers of each species hunted in their village. There were rumours that lemur hunting persists at some sites (Table 4). Birds are usually hunted for local consumption. There is not much commerce in these wild-caught birds and the hunting is more intense in villages with a lower standard of living.

Interviews undertaken during the monitoring indicate that lemur hunting persisted in 3 of the 16 villages in 2003, as opposed to 4 in 2002. In addition to this reported reduction in lemur hunting, the known area of lemur occupancy was extended by monitoring in 2003, when lemurs were found at Belempona in the north, where no lemurs had been seen since 1999 and they were believed to have disappeared.

Table 4. Quiz results in order of position in inter-village competition 2003 in Alaotra, Madagascar.

\begin{tabular}{|c|c|c|c|c|c|c|}
\hline & $\begin{array}{l}\text { Marsh } \\
\text { area } \\
\text { (ha) }\end{array}$ & $\begin{array}{l}\text { Correct } \\
\text { responses to } \\
\text { quiz } \\
\text { questions }(\%)\end{array}$ & $\begin{array}{l}\text { Area of } \\
\text { marsh } \\
\text { burned (ha) }\end{array}$ & $\begin{array}{l}\text { Fish } \\
<13 \mathrm{~cm} \\
\text { long }(\%)\end{array}$ & $\begin{array}{l}\text { Number } \\
\text { of birds } \\
\text { hunted }\end{array}$ & $\begin{array}{l}\text { Hunting } \\
\text { lemurs }\end{array}$ \\
\hline \multicolumn{7}{|c|}{ Small sites in $\mathrm{E}<1000$ ha } \\
\hline Andreba & 235 & 64 & 0 & 1 & 3 & No \\
\hline Ambatofotsy & 700 & 59 & 0 & 3 & 50 & Yes \\
\hline Ambatomanga & 70 & 43 & 0 & 0 & 0 & No \\
\hline Andromba & 180 & 29 & 0 & 84 & 1716 & No \\
\hline Amparihimpony & 15 & 34 & 0 & 9 & 3 & No \\
\hline Angoja & 400 & 16 & 300 & 12 & 12 & No \\
\hline \multicolumn{7}{|c|}{ Big sites in $\mathrm{SW}>1000$ ha } \\
\hline Andilana & 5700 & 61 & 0 & 0 & 60 & Yes \\
\hline Anororo & 9850 & 47 & 38 & 3 & 188 & No \\
\hline Ambodivoara & 1700 & 49 & 0 & 3 & 30 & No \\
\hline Antanifotsy & 1000 & 34 & 3 & 12 & 328 & Yes \\
\hline Anosibe & 1500 & 11 & 51 & 26 & 917 & No \\
\hline \multicolumn{7}{|c|}{ Small sites in $N<1000$ ha } \\
\hline Belempona & 300 & 40 & 0 & 4 & 44 & No \\
\hline Vohimarina & 300 & 54 & 0 & 1 & 1 & No \\
\hline Vohimena $^{\mathrm{a}}$ & 400 & - & 0 & 0 & 692 & No \\
\hline Ampasika & 140 & 11 & 0 & 1 & 214 & No \\
\hline Andrebakely ${ }^{\mathrm{a}}$ & 320 & - & 0 & 77 & 1371 & No \\
\hline Total & 22,810 & & 392 & & 5629 & \\
\hline
\end{tabular}

${ }^{\mathrm{a}}$ Quizzes were not held due to other events in the village. 
Local knowledge of biodiversity and ecology

There appears to be a strong correlation between level of knowledge (a higher $\%$ correct responses) and positive environmental management (less marsh burned, less hunting, fewer fish $<13 \mathrm{~cm}$ ) (Table 4). This suggests that environmental awareness and education leads to improved environmental management, and vice versa.

\section{Cost and effort of monitoring}

The following time input were provided by the participants:

1. Villagers 50 days (3-4 days per village).

2. Regional technicians (Government, NGO, local experts) 57 days.

3. Durrell Wildlife technicians 127 days.

The field missions for the monitoring in 2002 cost $\$ 4,825$, excluding the salaries of Durrell Wildlife and Government technicians, and the competition prizes cost $\$ 1,125$.

The total cost of the monitoring were divided on the following budget lines (in US\$; 2002-data): Travel (USD 325), Food and Accomodation (1935), Daily Salaries (1200), Materials (240), Prizes for quizzes (645) and Prize giving ceremonies (480).

\section{Wetland management actions}

The 2002 monitoring programme helped the regional fisheries service and fishing associations to amend the regional fishing convention. Several new destructive practices identified during the monitoring were banned, such as burning marshes to create fishing ponds and creating fences to retain fish. These fishing practices have not been observed in subsequent monitoring so the bans seem to have been respected. In July 2002, the regional fishing convention also banned hunting of locally endemic species and all the village by-laws have subsequently been similarly amended.

Several communities were keen to accelerate contractual transfer of marsh management with the regional forestry service following the monitoring, and the GPS (global positioning system) points and habitat maps from the monitoring assisted with this process. Habitat maps are also being used to guide a regional zoning exercise prior to the creation of the new protected area.

\section{Discussion}

\section{Technical capacity, data accuracy and long-term usefulness of the data}

There are only three years of data for this monitoring scheme so it is not yet possible to draw firm conclusions on long term trends. It is worth evaluating 
to what extent the adoption of these simple low-cost methods will provide effective long-term monitoring. The participatory nature of the monitoring contributed both positive and negative aspects. Working with local people facilitated use of their intimate knowledge of the area, for example where lemurs could be found. However, lemur and waterbird monitoring was very simplistic during the participatory monitoring, only noting presence and diversity of species. Over the long term such data will enable monitoring of a change in area of lemur occupancy, which is an important aspect of conservation status, but it will not enable precise detection of changes in population. The bird lists will only show if any species stopped using Alaotra wetland over the long term, and more extensive surveys will still be required for confirmation. More quantitative lemur and waterbird surveys require trained technical staff with a greater time and financial investment and these are currently undertaken separately by Durrell Wildlife so have not been described in this paper.

The village hunting surveys are not very reliable because the families chosen at random do not necessarily know the waterbirds and the estimates of the number of individuals and eggs taken varies with level of education, with type of livelihood activities and with age. Some old people get confused with what happened in the past and it is not clear they are responding with respect to the current year. Less educated people tend to be nervous and we are not sure if they give accurate estimates of the numbers. It is not clear how accurate the figures are for people who are not hunters themselves. Hunting figures from these surveys only indicate orders of magnitude of hunting of different species and which villages are most involved, which helps with targeting conservation action, but are not sufficiently robust to indicate trends.

The evaluation of areas burned is accurate to the error of the GPS unit, which is around $10 \mathrm{~m}$. We are confident that all burned areas are found by observation from high points and group interviews in villages, and that these data will be useful in monitoring long-term trends.

The fish catch data, although only for 3 years, gives an indication that fishermen's opinions that fish catches and fish sizes are increasing may be true. However, given the economic importance of fishing and the potential of linking increased fish catches with good environmental management and conservation, this aspect of the monitoring should be strengthened. For example the number of fish catches evaluated should be increased at each site to become more statistically robust and fish sizes should also be recorded.

\section{Transparency and good governance}

The participatory aspect of the monitoring improved collaboration between the villagers, the government technical services, regional NGOs and Durrell Wildlife. The participation of the Government technical services gave an opportunity to clarify the laws and responsibilities concerning natural 
resources. It increased contact and trust between Government agents and villagers and enabled them to visit marshes together rather than meeting in the village. The joint monitoring ensures that all parties know if there have been infractions. We believe that monitoring helped to reduce burning and clearance of marshes for rice fields because villagers were worried they would be caught and punished. The monitoring and the competition encouraged villagers to monitor each other's actions so that culprits could be identified if burned areas were found. Most villagers want to enforce laws concerning illegal or banned unsustainable practices but do not have sufficient authority so they welcome the presence of the Government agents.

The monitoring also encourages transparency and good governance from the Government agents as the public profile during the monitoring provides pressure not to indulge in corruption or partiality. For example, fisheries agents have become much more strict about enforcing fisheries regulations by confiscating fish caught illegally and burying them publicly and confiscating and destroying illegal nets and boats.

We believe that the generally positive effects of increased enforcement, an important aspect of good resource management, are likely to continue.

Government agents and village leaders make speeches during the public meetings in support of conservation and sustainable resource use, which clarifies and reinforces these as public policy. Once they have made speeches they are held more accountable for their actions and there is a motivation to practice what they preach. This provides leadership for other members of the community.

Vehicle for awareness raising and enlisting support for wetland management and monitoring

Even though the data presented here are insufficient to prove any real trends, the development of sustainable resource management rules and institutions and the apparent grass-roots interest and support for conservation lead us to be cautiously optimistic that these preliminary results will continue positively.

The villagers who participate in the monitoring become interested in the environmental changes and explain the results to their peers. More people want to join the team each year, despite a lower wage than from fishing. This could be because their participation gives them special standing as technical experts within the village and also because they get the opportunity and training to use technical materials like binoculars and GPS. In addition, more people join the community associations following the monitoring.

The announcement of the competition results and the prize-giving ceremonies provide an opportunity to involve dignitaries and get regional media coverage. This heightens the pride taken by each village in their monitoring results and also publicises the importance of wetland conservation and management. 
The quizzes, in particular, raise awareness of local biodiversity and the regional fishing convention. Local knowledge is reinforced by public repetition. The quizzes are an effective means of environmental education and further enhance the conservation impact of the monitoring. Monitoring was equally effective in generating data without the quiz but after quizzes were added we think there was broader awareness and interest throughout the community and a greater likelihood of leading to improved management actions. For example, we believe that the ecological monitoring helped raise awareness that led to amendments in the regional fishing convention and banning of hunting of certain species.

\section{Sustainability}

It is possible that this apparent interest in sustainable resource use and conservation has only led to temporary behaviour change and previous unsustainable practices that are economically attractive in the short term will return. The institutions and rules for sustainable resource use will help to ensure that the minority cannot plunder common resources at the expense of the majority. Only time will tell if this is effective and the monitoring programme will help to facilitate adaptive management by providing an indicator of when and where further action is required.

Sustainability of any monitoring programme depends on its usefulness to the managers, their capacity to implement it and its cost. We believe that the monitoring has been instrumental in raising interest in sustainable resource use and conservation, in particular because of its participatory nature and that future managers will continue the necessary effort and investment.

It is necessary to use GPS units, maps and computer applications to analyse and store the data. The villagers, communes and even the Government technical services do not currently have these materials or have the capacity to collect the data and do the analysis without support from Durrell Wildlife. This should be resolved by an investment in training and donation of such equipment. All the necessary equipment can be maintained in the capital city (225 $\mathrm{km}$ or $8 \mathrm{~h}$ drive away).

At around $\$ 5,000$ per year this monitoring programme is not particularly expensive which is a very important factor in ensuring sustainability. Monitoring is currently funded by Durrell Wildlife, with the aim that within the next 3 years the regional Ramsar Management Committee (NGO) will seek and manage future funding, ideally with a contribution from improved fish production. The relatively low cost of monitoring makes potential future transfer to a regional authority a feasible proposition, especially given the high economic importance of the region for rice and fish. If more sophisticated and higher cost monitoring had been developed, for example using satellite images and over-flights, such transfer would be much less likely. Designation as a Ramsar site and future gazetting as a protected area with a strict conservation 
area of at least 8,900 ha will help to ensure local, regional, national and will be an important lever for international support and potential funding.

We think that this kind of participatory monitoring could play a similar role in other wetlands in Madagascar and beyond. Participatory monitoring is particularly appropriate in wetlands because local inhabitants often rely heavily on the wetland resources for their livelihood, and the fisheries can improve with management measures that also favour biodiversity.

\section{Recommendations regarding monitoring methods}

On the basis of our experiences from this scheme, we recommend the following:

- Use simple methods that are easy to implement by villagers and Government partners.

- Avoid unnecessary changes in the monitoring methods.

- Separate the monitoring of populations of key species (lemur, waterbirds), which require greater technical capacity, from the participatory ecological monitoring.

- Try to ensure that the factors monitored include those with an economic or development interest for the villagers (such as fish), to help maintain their motivation.

\section{Conclusion}

The participatory ecological monitoring is becoming an accepted part of regional environmental management in Madagascar. The results have assisted the regional government development committee in preparing the regional development plan, and will help Madagascar to report to international conventions such as Ramsar and the Convention on Biological Diversity. We think that this approach could be adopted effectively by other developing countries where the livelihood of the citizens depends greatly on the sustainable use of natural resources to be monitored, which is often the case for wetlands. Participatory ecological monitoring not only encourages improved management and reduction of human-induced threats, but also fosters respect for biodiversity and wise use of natural resources.

\section{Acknowledgements}

This paper is an expanded version of a presentation we were invited to make at a symposium on locally-based monitoring in Denmark in April 2004 (www.monitoringmatters.org). The symposium was organised by the Nordic Agency for Development and Ecology (NORDECO, Denmark), and the Zoology Department of Cambridge University (UK). Funding from NORDECO enabled 
HTA to attend the symposium. The authors are very grateful to Ranaivoson Romain C. (Circonscription Scolaire Amparafaravola), Randrianarivo Albert (NGO Velombolo), Rakotomalala Haja N. (NGO Tany Maitso), Rasolonjatovo Richard (Association Zetra Maitso Andreba), Rakotonierana André (Association Vorontsara Andilana) for their direct help in the field, to Rakotondrasoa (Fisheries Service Amparafaravola), Randriamanolosoa Jean (Fisheries Service Ambatondrazaka) and Randriamisy H. Simon (Water and Forest Service Amparafaravola), Ranaivoarinosy (Water and Forest Service Ambatondrazaka) for their diligent assistance throughout the field work, and to Razanadrakoto Davida (Head of Fisheries Service Ambatondrazaka) and Randriambohanginjatovo René (Head of Water and Forests Service Ambatondrazaka) for their useful technical suggestions. This work was financially supported by Durrell Wildlife Conservation Trust, the Liz Claiborne Art Ortenberg Foundation, the Margot Marsh Biodiversity Foundation and Landscape Development Interventions (USAID). We are also grateful to F. Danielsen, J. Fjeldså and an anonymous reviewer for comments on an earlier version of this paper.

\section{References}

ANGAP 2001. Madagascar Protected Area System Management Plan. ANGAP, Antananarivo, Madagascar.

Andrianandrasana T.H. 2002. Etude de la régénération du marais d'Alaotra, habitat naturel du Hapalemur griseus alaotrensis. Durrell Wildlife Conservation Trust - Madagascar Programme, Antananarivo, Madagascar.

Andrianandrasana T.H., Ramanampamonjy J., Durbin J.C., Lewis R.E., Razafindrajao F., Rakotoniaina L.J., Randriamanampisoa H. and Randriamahefasoa J. 2002. Fiche technique sur les zones humides Ramsar : Le Lac Alaotra - les zones humides et le bassin versant. Ministry of Environment, Waters and Forests, Antananarivo, Madagascar.

Boylen C.W., Howe E.A., Bartkowski J.S. and Eichler L.W. 2004. Augmentation of a long-term monitoring program for Lake George, NY by citizen volunteers. Lake Reserv. Manage. 20: 121129.

Danielsen F., Mendoza M.M., Alviola P., Balete D.S., Enghoff M., Poulsen M.K. and Jensen A.E. 2003. Biodiversity monitoring in developing countries: what are we trying to achieve? Oryx 37: 407-409.

Engel S.R. and Voshell J.R. 2002. Volunteer biological monitoring: can it accurately assess the ecological condition of streams? Am. Entomol. 48: 164-177.

Gautier L. and Goodman S.M. 2003. Introduction to the flora of Madagascar. In: Goodman S.M. and Benstead J.P. (eds), The Natural History of Madagascar. University of Chicago Press, Chicago, USA, pp. 229-249.

Glaw F. and Vencesn M. 2003. Introduction to the amphibians. In: Goodman S.M. and Benstead J.P. (eds), The Natural History of Madagascar. University of Chicago Press, Chicago, USA, pp. 883-898.

Hawkins F., Andriamasimanana R., Seing S.T. and Rabeony Z. 2000. The sad story of Alaotra Little grebe Tachybaptus rufolavatus. Bull. African Bird Club 7: 115-117.

Hawkins A.F.A. and Goodman S.M. 2003. Introduction to the birds. In: Goodman S.M. and Benstead J.P. (eds), The Natural History of Madagascar. University of Chicago Press, Chicago, USA, pp. 1019-1044.

Langrand O. 1995. Guide des oiseaux de Madagascar. Delachaux et Niestlé, Lausanne, Switzerland. 
Mittermeier R.A., Tattersall I., Konstant W.R., Meyers D.M. and Mast R.B. 1994. Lemurs of Madagascar Edition. CI Tropical Field Guide. Series-Conservation International, Washington, DC, USA.

Mutschler T.W., Randrianarisoa J. and Feistner A.T.C. 2001. Population status of Alaotran gentle lemur Hapalemur griseus alaotrensis. Oryx 35: 152-157.

Pidgeon M. 1996. Lake Alaotra and Wetlands of Central and Eastern Madagascar. Missouri Botanical Gardens, Antananarivo, Madagascar.

PRD (Plan Régional de Développement) 2003. Zone de Développement Rural Intégré de l'Alaotra (Z.D.R.I). CORDAL, Ambatondrazaka, Madagascar.

Rakotonierana D. 2004. Rapport Annuel 2003 CIRAGRI. Circonscription d'Agriculture, Ambatondrazaka, Madagascar.

Raxworthy C.J. 2003. Introduction to the reptiles. In: Goodman S.M. and Benstead J.P. (eds), In: The Natural History of Madagascar. University of Chicago Press, Chicago, USA, pp. 934-949.

Razanadrakoto D. 2004. Rapport Annuel 2003 CIRPRH. Circonscription de la Pêche et des Ressources Halieutiques, Ambatondrazaka, Madagascar.

Townsend W.R., Borman A.R., Yiyoguaje E. and Mendua L. 2005. Cofán Indians' monitoring of freshwater turtles in Zábalo, Ecuador. Biodivers. Conserv. 14: 2743-2755. 